\title{
Potential Inhibitory Influence of miRNA 210 on Regulatory T Cells during Epicutaneous Chemical Sensitization
}

\author{
Carrie Mae Long ${ }^{1,2}$, Ewa Lukomska ${ }^{2}$, Nikki B. Marshall ${ }^{2,+}$, Ajay Nayak ${ }^{2}$ and Stacey E. Anderson ${ }^{2, *}$ \\ 1 Immunology and Microbial Pathogenesis Graduate Program, West Virginia University, Morgantown, \\ WV 26505, USA; clong14@mix.wvu.edu \\ 2 Centers for Disease Control and Prevention, National Institute for Occupational Safety and Health, \\ Allergy and Clinical Immunology Branch, Morgantown, WV 26505, USA; uvm3@cdc.gov (E.L.); \\ nikki.marshall@inovio.com (N.B.M.); ajay.nayak@jefferson.edu (A.N.) \\ * Correspondence: dbx7@cdc.gov; Tel.: +1-304-285-6024 \\ † Current address: Inovio Pharmaceuticals, Inc., 660 West Germantown Pike, Plymouth Meeting, \\ PA 19462, USA.
}

Academic Editor: Paolo Cinelli

Received: 27 September 2016; Accepted: 19 December 2016; Published: 27 December 2016

\begin{abstract}
Toluene diisocyanate (TDI) is a potent low molecular weight chemical sensitizer and a leading cause of chemical-induced occupational asthma. The regulatory potential of microRNAs (miRNAs) has been recognized in a variety of disease states, including allergic disease; however, the roles of miRNAs in chemical sensitization are largely unknown. In a previous work, increased expression of multiple miRNAs during TDI sensitization was observed and several putative mRNA targets identified for these miRNAs were directly related to regulatory $\mathrm{T}-\mathrm{cell}\left(\mathrm{T}_{\text {reg }}\right)$ differentiation and function including Foxp3 and Runx3. In this work, we show that miR-210 expression is increased in the mouse draining lymph node (dLN) and $\mathrm{T}_{\text {reg }}$ subsets following dermal TDI sensitization. Alterations in dLN mRNA and protein expression of $\mathrm{T}_{\text {reg }}$ related genes/putative miR-210 targets (foxp3, runx3, ctla4, and cd25) were observed at multiple time points following TDI exposure and in ex vivo systems. $A T_{\text {reg }}$ suppression assay, including a miR-210 mimic, was utilized to investigate the suppressive ability of $\mathrm{T}_{\text {regs. }}$. Cells derived from TDI sensitized mice treated with miR-210 mimic had less expression of miR-210 compared to the acetone control suggesting other factors, such as additional miRNAs, might be involved in the regulation of the functional capabilities of these cells. These novel findings indicate that miR-210 may have an inhibitory role in $\mathrm{T}_{\text {reg }}$ function during TDI sensitization. Because the functional roles of miRNAs have not been previously elucidated in a model of chemical sensitization, these data contribute to the understanding of the potential immunologic mechanisms of chemical induced allergic disease.
\end{abstract}

Keywords: microRNA; regulatory T cell; immunotoxicology; toluene diisocyanate; isocyanate; miR-210

\section{Introduction}

Occupational allergic disease is a significant health burden. A variety of diseases can be caused by workplace chemical exposures, including asthma, conjunctivitis, dermatitis, rhinitis, and urticaria [1]. Diisocyanates are a group of highly reactive chemicals characterized by the presence of double isocyanate functional groups; many of these chemicals are potent sensitizers and major causative agents of occupational allergic disease [2-4]. Toluene diisocyanate (TDI) is frequently utilized in the automobile industry and in the manufacture of polyurethane foams, paints, and coatings [5-8]. TDI is widely used throughout the U.S. and around the globe; the U.S. Environmental Protection Agency reports that U.S. production and importation of 2-4 and 2-6 TDI isomers rose above one 
billion pounds in 2006 [6]. While TDI has generally been classified as a T-helper type 2 (Th2) sensitizer, the immune response following exposure is more accurately characterized as a mixed Th1/Th2 response in both rodents and humans [1,2,9]. The principal routes of human exposure to TDI are inhalation and dermal contact [6] and sensitization leading to allergic disease has been documented for both routes $[7,10]$. Once the induction threshold has been reached, skin sensitization is thought to be sufficient for subsequent allergic disease of the respiratory tract [7], illustrating the systemic nature of TDI sensitization. Although TDI-induced allergic disease is an extremely relevant occupational health concern the pathogenic mechanisms of diisocyanate-induced allergic disease are not fully understood [5]. The identification of novel mediators of allergic disease may be necessary to obtain a full and complete understanding of the disease. Because of the occupational significance of and lack of validated identification strategies for chemical respiratory sensitizers like TDI [4,11], it is necessary to investigate and identify functional pathways and mechanisms that are involved in TDI sensitization. Specific understanding of disease mechanism may have direct implications in risk assessment, hazard communication and guidance used in the selection of safe products, work place interventions and training programs to warn workers about potential risks, the identification of safer alternatives, and the selection of proper personal protective equipment (PPE).

An emerging class of epigenetic regulatory elements that have been the subject of recent scientific focus are microRNAs (miRNAs). These molecules are single stranded, noncoding RNA molecules that are approximately 19-23 nucleotides long [12]. miRNAs exhibit functional significance though posttranscriptional gene regulation due to their ability to bind to the target mRNA and destabilize and inhibit protein translation when in complex with Argonaute proteins and the RNA-induced silencing complex (RISC). The seed sequence of a mature miRNA interacts with the $3^{\prime}$ untranslated region of target mRNA and leads to the translational repression or degradation of the target mRNA, influencing gene expression. Recently, it has been shown that miRNAs play a major role in a variety of immune responses [13-16]. These regulatory factors have not been functionally investigated in the context of chemical sensitization, with the exception of recent work by our group that profiled the general expression kinetics of miRNAs involved in TDI sensitization [1] and research profiling miRNA expression in both human and murine diphenylcyclopropenone-induced dermatitis [17].

The identification of increased expression of several miRNAs in the draining lymph nodes (dLN) of mice during epicutaneous TDI sensitization prompted further investigation into the potential functional roles of these molecules in the allergic response. Target analysis for upregulated miRNAs (miR-210, -31, and -155) revealed several putative and confirmed regulatory $\mathrm{T}$ cell $\left(\mathrm{T}_{\text {reg }}\right)$-related targets including foxp3 and runx3 in murine and human genomes [1]. These transcription factors and the signaling molecules CD25 and CTLA4 are integral to $\mathrm{T}_{\text {reg }}$ differentiation and function. The expression of these molecules allows $\mathrm{T}_{\text {reg }}$ to differentiate in response to allergens and exert immunoregulatory functions, dampening inappropriate inflammatory and adaptive immune responses. In addition, miR-31 and -155 have been implicated as regulators of $T_{\text {reg }}$ in a variety of contexts $[18,19]$. A role for $\mathrm{T}_{\text {regs }}$ has been suggested in models of chemical-induced contact hypersensitivity $[20,21]$ and, in a recent manuscript, Long et al. demonstrated the increased expression and functional capability of $\mathrm{T}_{\text {regs }}$ during TDI sensitization [21]. While the collection of data regarding roles for $\mathrm{T}_{\text {regs }}$ and miRNAs in chemical allergy is growing, it is still limited. Recently published data suggests an important role for $T_{\text {regs }}$ in dermal TDI sensitization, yet the interaction between these cells and selected miRNAs has not been investigated. While miR-210 is well characterized in the hypoxia response, its specific role in allergic disease has not yet been defined. In the present study, we utilized a murine model of epicutaneous TDI sensitization in order to elucidate the expression kinetics and role of miR-210 and its putative mRNA targets in a murine model of epicutaneous TDI sensitization, specifically in relation to the $\mathrm{T}_{\text {reg }}$ subset. 


\section{Materials and Methods}

\subsection{Mice}

Female BALB/c mice (6-8 weeks of age) were obtained from Taconic (Germantown, NY, USA), acclimated for 5 days, and then randomly assigned to treatment group; homogenous weight distribution was ensured across treatment groups. Mice were housed in ventilated plastic shoebox cages with hardwood chip bedding at a maximum of five animals per cage. A NIH-31 modified 6\% irradiated rodent diet (Harlan Teklad, Frederick, MD, USA) and tap water were administered ad libitum. Housing facilities were maintained at $68-72^{\circ} \mathrm{F}$ and $36 \%-57 \%$ relative humidity, and a $12 \mathrm{~h}$ light-dark cycle was maintained. All animal experiments were performed in the Association for Assessment and Accreditation of Laboratory Animal Care (AAALAC) accredited National Institute for Occupational Safety and Health (NIOSH) animal facility in accordance with an Institutional Animal Care and Use Committee-approved protocol (protocol number 15-SA-M-004, date of approval 1 August 2015).

\subsection{TDI Sensitization Model}

Toluene 2,4-diisocyanate (TDI, CAS\# 584-84-9) was obtained from Sigma-Aldrich (Milwaukee, WI, USA). Animals were exposed to a single dose of $0 \%, 0.5 \%$, and $4 \%$ TDI $(v / v)$ on the dorsal surface of each ear ( $25 \mu \mathrm{L}$ per ear). The chosen TDI concentrations $(0.5 \%$ and $4 \% v / v)$ and dosing regimen was previously shown to induce sensitization [1,21] and 4\% TDI (1000 $\mu \mathrm{g}$ TDI/ $\left.\mathrm{cm}^{2}\right)$ was previously reported as the minimum single dose concentration of TDI that could induce maximum sensitization in the absence of systemic toxicity [1]. Acetone was selected as the vehicle control and has been historically utilized in our laboratory to evaluate chemical sensitization [21-23]. It is important to note that due to hydrolysis, slight variations in the concentration of TDI dosing solutions may have occurred between preparation and application. However, animals were exposed within 30 min of TDI preparation and no visualization of hydrolysis was observed subsequent to exposures.

\subsection{Euthanasia, Tissue Collection, and Processing}

Animals were weighed, euthanized via $\mathrm{CO}_{2}$ asphyxiation at time points ranging from 1 to 11 days post chemical exposure, and examined for gross pathology. Left and right auricular draining lymph nodes (dLNs; drain the site of chemical application) were collected in $4 \mathrm{~mL}$ sterile phosphate-buffered saline (PBS, pH 7.4) and manually dissociated using the frosted ends of two microscope slides. Cells were counted using a Cellometer (Nexcelom Bioscience, Lawrence, MA, USA) and size exclusion parameters $(3.5$ to $36 \mu \mathrm{m}$ ) with a combined acridine orange/propidium iodide solution to identify viable cells. For isolation of specific cellular subsets Stemcell magnetic isolation kits (Vancouver, BC, Canada) were utilized, including the $\mathrm{T}_{\text {reg }}$ isolation kit (CD4 negative and CD25 positive selection).

\subsection{Ex Vivo miRNA Transfection Assays}

Following dLN processing and counting, miR-31, -155, and -210 mimics (25 pmol in Lipofectamine transfection reagent, ThermoFisher, Waltham, MA, USA) were reverse transfected in flat-bottom 24-well plates for $24 \mathrm{~h}$. Then, $1.5 \times 10^{6}$ naïve or acetone-treated dLN cells $/ \mathrm{mL}$ (in RPMI-1640 media) were added to plates followed by general $\mathrm{T}$ cell stimulation $(2 \mu \mathrm{g} / \mathrm{mL} \alpha-\mathrm{CD} 3,1 \mu \mathrm{g} / \mathrm{mL} \alpha-\mathrm{CD} 28$ and incubated in fresh media at $37{ }^{\circ} \mathrm{C}$ and $5 \% \mathrm{CO}_{2}$. Following a $72 \mathrm{~h}$ incubation, cells were washed with RPMI-1640 and RNA was isolated as described in the following section. RNA was assayed for intracellular miRNA expression to conform the intracellular uptake of miRNA mimics as well as $\mathrm{T}_{\text {reg-related gene expression via RT-PCR. }}$ 


\subsection{RNA Isolation, Reverse Transcription, and RT-PCR}

Total RNA was isolated from the dLN using the miRNeasy kit (Qiagen, Hilden, Germany) according to the manufacturer's directions. A QiaCube (Qiagen) automated RNA isolation machine was utilized in conjunction with the specified RNA isolation kit. The concentration and purity of the RNA was determined using a ND-1000 spectrophotometer (Thermo Scientific Nanodrop, Wilmington, DE, USA). For gene and primary miRNA expression analysis, first strand cDNA synthesis was performed using a High-Capacity cDNA Synthesis Kit (Applied Biosystems, Carlsbad, CA, USA) according to the manufacturer's recommendations. For mature miRNA, reverse transcription TaqMan MicroRNA Assays (looped-primer RT-PCR; Applied Biosystems) were utilized according to manufacturer's recommendations (both multiplex and singleplex protocols were utilized).

For analysis of mRNA and primary miRNA expression, TaqMan Universal Fast master mix (Life Technologies, Carlsbad, CA, USA), cDNA, and mouse-specific mRNA primers (TaqMan Custom PCR Arrays, Carlsbad, CA, USA) were combined and PCR was performed according to the manufacturer's protocol (TaqMan Gene Expression Analysis). For analysis of miRNA expression, TaqMan Universal $2 \times$ master mix, No AmpErase UNG (Life Technologies), cDNA, and mouse-specific miRNA primers (TaqMan Custom PCR Arrays) were combined and PCR was performed according to manufacturer protocol (TaqMan miRNA Assays both Single- and Multi-Plex). Primers used include: $\beta$-actin, cd25 (il2r $\alpha$ ), ctla4, foxp3, mature miR-210, -31, -155, primary miR-210, runx3, and sno 234 . MicroAmp Fast Optical 96-well reaction plates were analyzed on an Applied Biosystems 7500 Fast Real Time PCR system using cycling conditions as specified by the manufacturer. $\beta$-actin (mRNA and primary miRNA) and snoRNA234 (miRNA) were used as the endogenous reference control gene as expression was determined to be stable following chemical exposure (data not shown). RT-PCR data were collected and represented as relative fold change over vehicle control, calculated by the following formula: $2^{-\Delta \Delta \mathrm{Ct}}=\Delta \mathrm{Ct}_{\text {Sample }}-\Delta \mathrm{Ct}_{\text {Control }}$. $\Delta \mathrm{Ct}=\mathrm{Ct}_{\text {Target }}-\mathrm{Ct}_{\beta \text {-ACTIN }}$, where $\mathrm{Ct}=$ cycle threshold as defined by manufacturer.

\subsection{Flow Cytometric Analysis and $T_{\text {reg }}$ Phenotyping}

Single cell suspensions were prepared from tissues and a minimum of 150,000 dLN cells were aliquoted into 96-well U-bottom plates and washed in fluorescence-activated cell sorting (FACS) staining buffer (PBS $+1 \%$ bovine serum albumin $+0.1 \%$ sodium azide). Cells were resuspended in staining buffer containing anti-mouse CD16/32 antibody (clone 2.4G2; BD Biosciences, San Jose, CA, USA) for blocking of $F_{C}$ receptors to minimize nonspecific binding. Cells were resuspended in staining buffer containing a cocktail of fluorochrome-conjugated antibodies specific for cell surface antigens including: CD3 (500A2, V500, BD Biosciences, Franklin Lanes, NJ, USA), CD4 (RM4-5, AF700, BD), CD8a (53-6.7, AF488, BioLegend, San Diego, CA, USA), CD25 (PC61, APC Cy7, BioLegend), CD45 (30-F11, PE, BD). Following surface staining, cells were washed in staining buffer and fixed using the Foxp3 fixation buffer set (eBioscience, San Diego, CA, USA). After overnight incubation in staining buffer, cells were permeablilized using the Foxp3 fixation buffer set (eBioscience) and re-suspended in permeabilization buffer containing a cocktail of fluorochrome-conjugated antibodies specific for intracellular antigens including: RUNX3 (R3-5G4, PE, BD), Foxp3 (FLK-16s, eF450 and APC, eBioscience). Following staining, cells were re-suspended in staining buffer and analyzed on an LSR II flow cytometer using FacsDiva software (BD Biosciences). Data analysis was performed with FlowJo 10.0 software (TreeStar Inc., Ashland, OR, USA). A minimum of 10,000 events were captured for each sample. Leukocytes were first identified by their expression of CD45. The $\mathrm{T}_{\text {reg }}$ subset was further identified as $\mathrm{CD}^{+} \mathrm{CD}^{+} \mathrm{CD} 8{ }^{-} \mathrm{CD} 25^{+} \mathrm{Foxp}^{+}$. Numerical population values were calculated by applying subset frequencies to the initial cell count obtained following lymph node homogenization. Compensation controls were performed using single stained cellular suspensions and OneComp beads (eBioscience, San Diego, CA, USA) and fluorescence minus one (FMO) staining controls were included to help set gating boundaries. 


\section{7. $T_{\text {reg }}$ Suppression Assay}

The suppressive ability of $\mathrm{T}_{\text {regs }}$ was analyzed using an ex vivo $\mathrm{T}_{\text {reg }}$ suppression assay as described by Long et al. [21] with modifications. This assay evaluates the ability of naïve, conventional dLN-derived $\mathrm{T}$ cells $\left(\mathrm{T}_{\text {cons }}\right)$ to proliferate in the presence of varying numbers of $\mathrm{T}_{\text {regs }}$ isolated from acetone- or TDI-exposed mice. Mice were exposed to acetone $(n=7-11)$ or TDI $(4 \%)(n=4-5)$ as previously described and following sacrifice at 7 days (peak of the expansion) post TDI exposure the $\mathrm{dLN}$ and spleens were removed. $\mathrm{T}_{\text {regs }}\left(\mathrm{CD} 4^{+} \mathrm{CD} 25^{+}\right)$and $\mathrm{T}_{\text {cons }}\left(\mathrm{CD} 4{ }^{+} \mathrm{CD} 25^{-}\right)$were isolated from the lymph nodes and $\mathrm{CD}^{-}$accessory cells were isolated from naïve spleens using CD4 negative and CD25 positive selection-based magnetic separation kits (Stemcell, Vancouver, BC, USA). Average $\mathrm{T}_{\text {reg }}$ purity is as follows for 7 days. Acetone: $96.5 \% \pm 0.8 \%$ of $\mathrm{CD}^{+} \mathrm{CD}^{+}$cells. $4 \%$ TDI: $97.35 \% \pm 0.25 \%$ of $\mathrm{CD}^{+} \mathrm{CD}^{+}$cells. Following isolation from naïve mouse dLNs, $\mathrm{T}_{\text {cons }}$ were labeled with $2 \mu \mathrm{M}$ carboxyfluorescein succinimidyl ester (CFSE). miR-210 mirVana mimic (2 pmol; ThermoFisher) in Lipofectamine RNAiMAX (ThermoFisher) or Lipofectamine only control (LO) were added to a 96-well U-bottom plate in order to reverse transfect cells. $\mathrm{T}_{\text {cons }}$ and $\mathrm{T}_{\text {regs }}$ were cultured in a 96-well U-bottom plate with anti-CD3 $\left(0.2 \mu \mathrm{g} / \mathrm{mL}\right.$; BD Biosciences) and accessory cells (naïve CD4 ${ }^{-}$splenocytes treated with mitomycin $\mathrm{C})$ at a variety of $\mathrm{T}_{\text {con }}: \mathrm{T}_{\text {reg }}$ ratios $(1: 1,2: 1,4: 1$, and 8:1). Additional controls included stimulated $\mathrm{T}_{\text {cons }}$ only to assess baseline proliferation, $\mathrm{T}_{\text {regs }}$ only, accessory cells only, and $\mathrm{T}_{\text {cons }}$ only with no stimulation nor accessory cells. Cells from each treatment group were pooled and added to triplicate wells of the culture plate. Seventy-two hours following plating, cells were stained with anti-CD4 and Live/Dead Violet (Life Technologies). $\mathrm{T}_{\text {cons }}$ were defined as $\mathrm{CD}^{+} \mathrm{CFSE}^{+}$cells and suppression was measured based on changes in the frequency of dividing $\mathrm{CFSE}^{+}$cells based on the dilution of CFSE. $T_{\text {regs }}$ were analyzed for purity based on their expression of CD3, CD4, and Foxp3 as determined by flow cytometric analysis as previously described.

\subsection{Statistical Analysis}

Statistical analyses were generated using GraphPad Prism version 5.0 (San Diego, CA, USA). Data were analyzed by a Student $t$-test comparing groups as indicated in the figure legends. Figure $4 \mathrm{C}$ was analyzed by analysis of variance using PROC MIXED. In some cases, data were transformed using the natural $\log$ to meet the assumptions of the analysis. Significant interactions were explored utilizing the "slice" option in PROC MIXED and pairwise differences were assessed using a Fisher's Least Significant Difference Test. All differences were considered significant at $p<0.05$; representative significance symbols varied by figure, as indicated in the legend.

\section{Results}

\subsection{Examination of miR-210 Expression during TDI Sensitization}

The kinetics of mature miR-210 expression were investigated via RT-PCR in the dLN following $0.5 \%$ and $4 \%$ TDI exposure. As previously reported [1], dLN miR-210 increased at various time points during $0.5 \%$ and $4 \%$ TDI sensitization, including four $(4 \%)$, seven, and nine $(0.5 \%$ and $4 \%)$ days post single exposure, with expression appearing to peak at four days post $4 \%$ TDI exposure (Figure 1A). Primary miRNA (pri-miRNA) transcripts represent the early precursor stage of mature miRNA structure prior to modification and cleavage by Drosha and Dicer. Pri-miR-210 levels were analyzed in the dLN at four days post TDI exposure, which represents the relative peak of dLN miR-210 expression. Although expression of pri-miR-210 was detected in the dLN, no significant alterations were observed. Alternatively, pri-miR-210 expression significantly decreased in the CD4 ${ }^{+}$ subset during 4\% TDI sensitization (Figure 1B). 
A

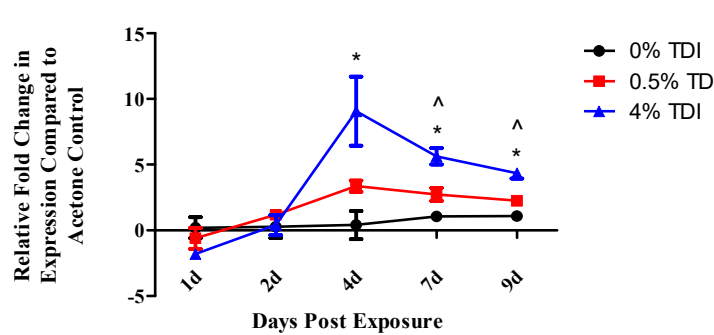

B

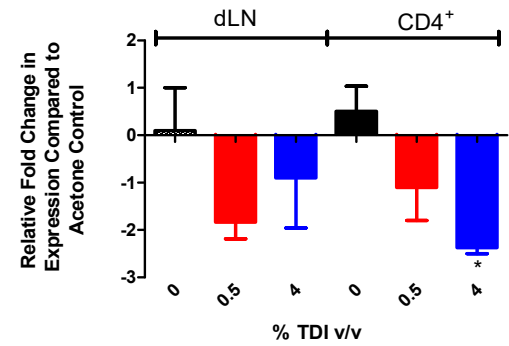

Figure 1. Mature and primary miR-210 expression increases in the draining lymph node (dLN) and $\mathrm{CD}^{+}$subsets following toluene diisocyanate (TDI) sensitization: RT-PCR analysis of mature miR-210 expression in the dLN at various time points post TDI exposure (A); and primary miR-210 expression in the whole dLN and $\mathrm{dLN} \mathrm{CD}^{+}$subset four days post TDI exposure (B). Cellular purity was assessed via flow cytometric staining for $\mathrm{CD}^{+}$Cells ( $\% \mathrm{CD}^{+}$of all cells; Acetone: $89.6 \% \pm 2.2 \%, 0.5 \%$ TDI: $91.5 \% \pm 0.3 \%$, and $4 \%$ TDI: $90.4 \% \pm 0.3 \%$ ). Bars represent mean relative fold change ( \pm standard error, SE) of 3-5 mice per group. Statistical significance is represented by ^ $(0.5 \%$ TDI) and * $4 \%$ TDI $)$ $(p<0.05)$ compared to vehicle control.

\subsection{Ex Vivo miR-210 Mimic Transfection Reveals Potential Inhibitory Effect of miR-210 on $T_{\text {reg-Related Genes }}$}

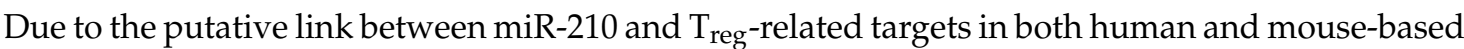
studies and target algorithms [1], an ex vivo transfection and stimulation assay was set up to directly

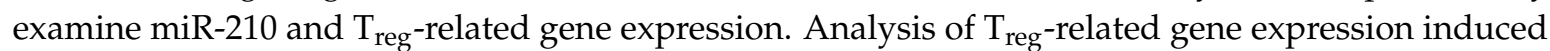
by the addition of excess levels of miR-210 was examined. Although not statistically significant, Figure 2A reveals increased miR-210 expression in cells treated with miR-210 mimic (101 fold) as compared to lipofectamine only (LO) control (1.2 fold). Analysis of $\mathrm{T}_{\text {reg-related genes revealed }}$

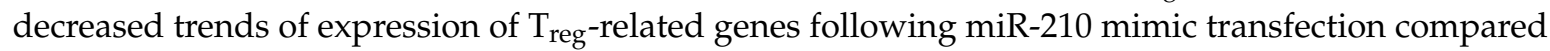
to the LO control, including foxp3 ( -2.0 fold compared to 0.6 fold) and $c d 25$ (( -3.2 fold compared to 0.2 fold) (Figure 2B)). No apparent changes in runx3 or ctla4 were observed (data not shown).

A
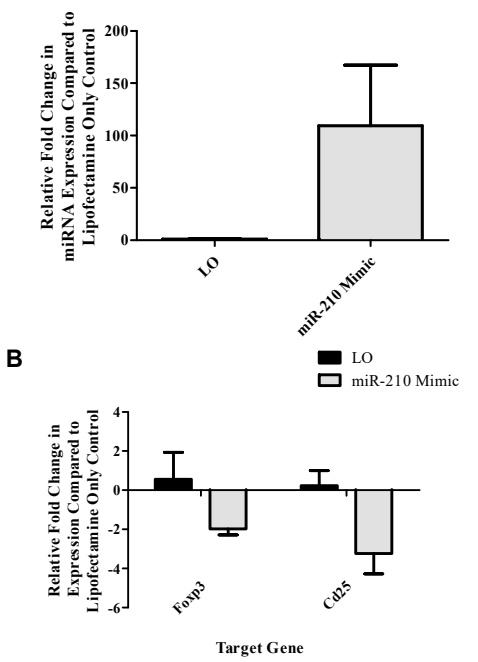

Figure 2. Ex vivo miR-210 mimic augmentation reveals potential inhibitory effect of miR-210 on regulatory $\mathrm{T}$ cell $\left(\mathrm{T}_{\text {reg }}\right.$ )-related genes in dLN cells. (A) Intracellular miR-210 was quantified via RT-PCR in ex vivo stimulated samples $72 \mathrm{~h}$ following transfection with lipofectamine only control (LO) or miR-210 mimic. (B) foxp3 and $c d 25$ (il2r $r$ ) were investigated as potential miRNA targets via RT-PCR. Bars represent mean relative fold change $( \pm S E)$ of 3 replicates per group. 


\subsection{In Vivo dLN Target Expression Reveals Decreased Expression of Several Key $T_{\text {reg }}$-Related Genes}

The expression of potential miR-210 targets and key $\mathrm{T}_{\text {reg genes potentially affected by miR-210 }}$ was investigated in the whole dLN at various time points following $4 \%$ TDI exposure. Similar to the findings of the ex vivo study and previously reported findings, dLN target/key player mRNA expression was significantly decreased at four ( $r u n x 3)$, seven (foxp 3$)$, and nine (foxp 3 ) days post $4 \%$ TDI exposure (Figure 3A,B). Foxp3 expression was decreased by approximately threefold in comparison to the acetone control at seven and nine days post TDI exposure (Figure 3A). Early statistically significant increases in foxp 3 (one day) and runx3 (two day) were also observed but only for a single time point and not determined to be of biological significance. dLN ctla4 and $c d 25$ expression significantly increased with peak expression at four and two days post $4 \%$ TDI exposure, respectively. However, these increases in expression were not maintained at later time points (Figure 3C,D).
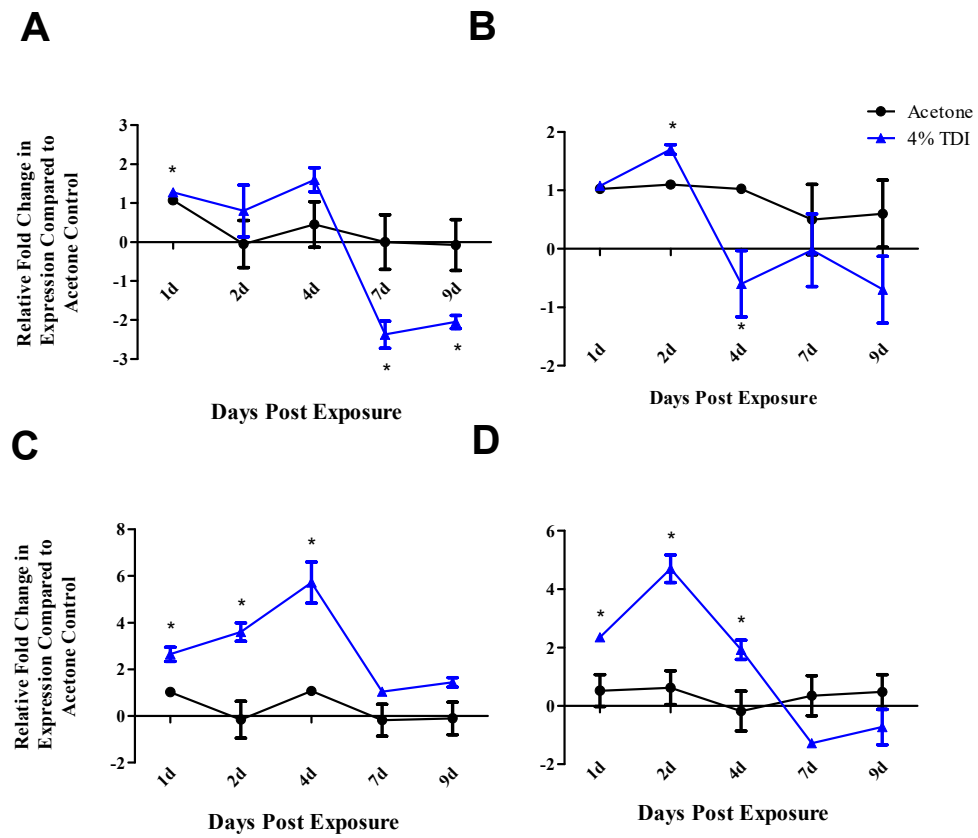

Figure 3. In vivo dLN mRNA expression of potential miR-210 targets reveals altered expression during TDI sensitization. RT-PCR analysis of: foxp3 (A); runx3 (B); ctla4 (C); and cd25 (D) expression in the whole dLN at various time points post $0 \%$ and $4 \%$ TDI exposure. Bars represent mean relative fold change $( \pm \mathrm{SE})$ of five mice per group. Statistical significance is represented by $*(p<0.05)$ compared to the vehicle control.

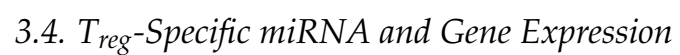

Due to the suspected influence of miR-210 on $\mathrm{T}_{\text {regs }}$, the levels of this miRNA were examined in $\mathrm{T}_{\text {regs }}\left(\mathrm{CD} 4^{+} \mathrm{CD} 25^{+}\right)$from the dLN of mice treated with $0 \%, 0.5 \%$, and $4 \%$ TDI at two and seven days post exposure. These time points were selected to reflect early and peak miR-210 and $\mathrm{T}_{\text {reg }}$ responses in the dLN (Figure 1A and [1]). While no statistically significant changes were observed following two days of exposure, miR-210 levels were significantly increased in $\mathrm{T}_{\text {regs }}$ during $0.5 \%$ and $4 \%$ TDI sensitization in a dose responsive fashion at seven days post exposure (Figure 4A). Expression of

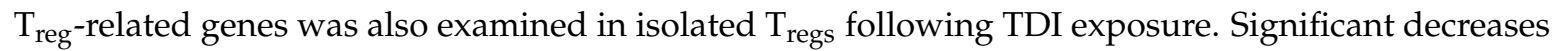
in foxp3, ctla4, runx3, and $c d 25$ were observed at both concentrations (except for $c t l a 4$ at $4 \%$ ) at two days post exposure (Figure 4B). Similarly, significant decreases in foxp3, ctla4, and $c d 25$ mRNA were observed in $\mathrm{T}_{\text {regs }}$ from $4 \%$ TDI-exposed mice at seven days post $4 \%$ TDI exposure (Figure $4 \mathrm{C}$ ), further indicating that these genes may be influenced by miR-210 (Figure 1A). $\mathrm{T}_{\text {reg-specific expression of }}$ runx 3 was assayed in $\mathrm{dLN}_{\text {regs }}$ during TDI sensitization. In contrast to the mRNA levels, increases in 
frequency and numbers of Runx $3^{+} \mathrm{T}_{\text {regs }}$ at all time points were observed following $0.5 \%$ and $4 \%$ TDI exposure (Figure 4D,E).

\section{A}

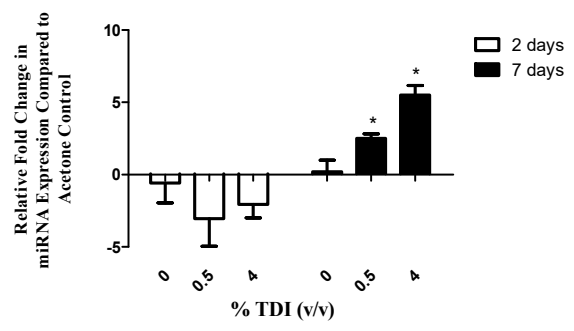

B

C
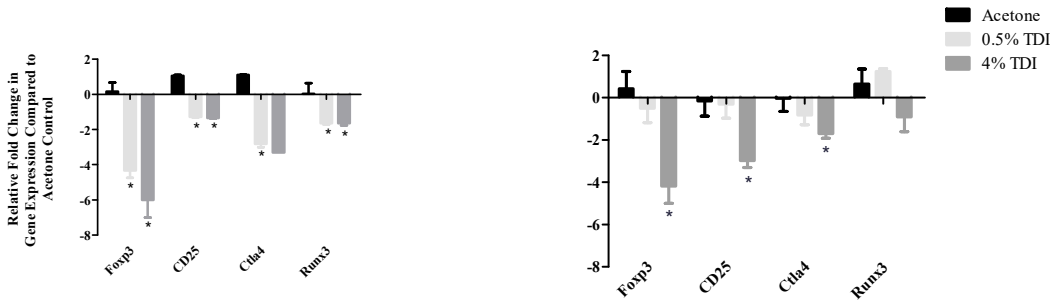

D

$\mathbf{E}$
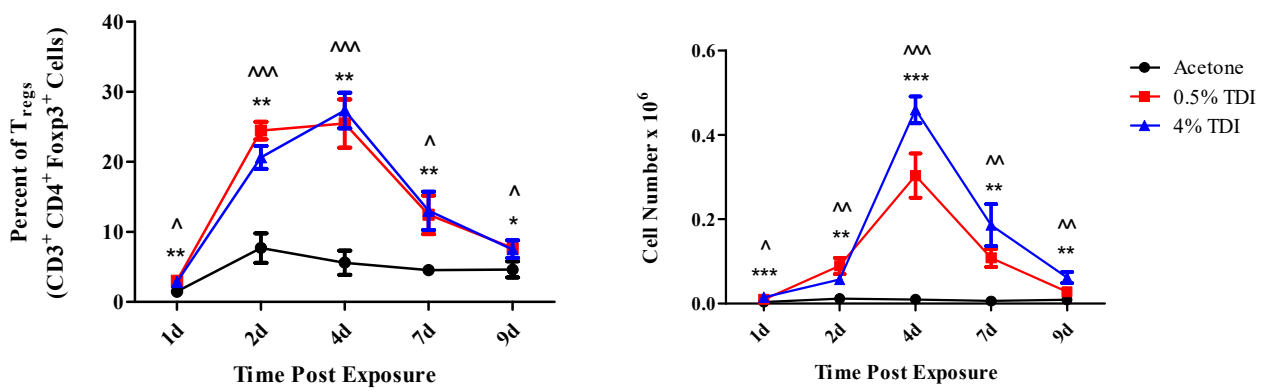

Figure 4. Mature miRNA and Runx3 expression increases in $\mathrm{T}_{\text {regs }}$ during TDI sensitization. RT-PCR

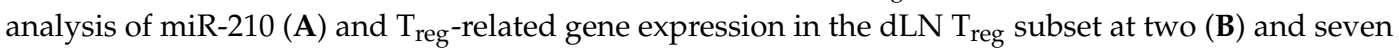
days (C) post TDI exposure. $\mathrm{T}_{\text {regs }}$ were isolated as $\mathrm{CD}^{+} \mathrm{CD}_{2} 5^{+}$cells and cellular purity was assessed via flow cytometric staining for $\mathrm{CD}^{+} \mathrm{CD}^{+} \mathrm{Foxp}^{+}$events (2 days: $\% \mathrm{~T}_{\text {regs }}$ of all $\mathrm{CD} 4^{+}$events, mean, $n=4-5$ per group: Acetone: $83.8 \% \pm 1.6 \%, 0.5 \%$ TDI: $67.1 \% \pm 4.2 \%$, and $4 \%$ TDI: $72.3 \% \pm 1.9 \% ; 7$ days: $\% \mathrm{~T}_{\text {regs }}$ of all CD4 $4^{+}$events: Acetone: $91 \%, 0.5 \%$ TDI: $88.4 \%$, and $4 \%$ TDI: $\left.86.7 \%\right)$. Flow cytometric analysis of dLN Runx $3^{+} \mathrm{T}_{\text {reg }}$ frequency $(\mathbf{D})$ and number $(\mathbf{E})$ following TDI sensitization. Bars represent mean relative fold change $( \pm \mathrm{SE})$ of $4-5$ mice per group. Significance is indicated by * $p \leq 0.05$ for $(\mathrm{A}-\mathrm{C})$ and $p \leq 0.05\left(^{(*)}, p \leq 0.01\left(^{* *}\right), p \leq 0.001\left(^{* * *}\right)\right.$, and $p \leq 0.0001\left(^{* * *}\right)$ for $4 \%$ TDI or $p \leq 0.05\left(^{(}\right), p \leq 0.01$ $\left({ }^{\wedge}\right), p \leq 0.001\left({ }^{\wedge}\right)$, and $p \leq 0.0001\left({ }^{\wedge \wedge}\right)$ for $0.5 \%$ TDI compared to vehicle control (D,E).

\subsection{The Ex Vivo Suppressive Capability of $T_{\text {regs }}$ Is Influenced by miR-210 Levels}

In order to examine the suspected inhibitory role of miR-210 on $\mathrm{T}_{\text {regs }}$ during TDI sensitization, the functional capabilities of $\mathrm{T}_{\text {regs }}$ were tested in an ex vivo suppression assay. miR-210 mimic was 
transfected in selected wells utilizing a lipid-based transfection strategy and intracellular miR-210 mimic uptake was confirmed in these wells at the time of cellular harvest (Figure 5A). Interestingly, following addition of the miR-210 mimic, miRNA-210 levels were almost 10-fold higher in wells containing acetone $T_{\text {regs }}$ compared to those with TDI $T_{\text {regs }}$ (Figure $5 \mathrm{~A}$ ). No differences were noted between miR-210 levels among the acetone and TDI groups treated with LO (Figure 5A). Significant baseline $T_{\text {reg }}$ suppressive ability was observed in wells with Lipofectamine only and acetone-derived $\mathrm{T}_{\text {regs }}$ as well as $4 \%$ TDI-derived $\mathrm{T}_{\text {regs }}$ (data not shown). This was not altered significantly upon the addition of miR-210 mimic with the exception of the $1: 1$ ratio in wells with $4 \%$ TDI-derived $\mathrm{T}_{\text {regs }}$ (data not shown). As previously evidenced [21], TDI-derived $\mathrm{T}_{\text {regs }}$ exhibited greater suppressive capability than acetone-derived $T_{\text {regs }}$ in mimic-treated wells for the 1:1, 2:1, 4:1, and 8:1 ratios (Figure 5B). This increased function was observed in the presence of lower miR-210 levels suggesting that TDI may induce additional factors that might influence the functional capabilities of the $\mathrm{T}_{\text {regs }}$.

\section{A}

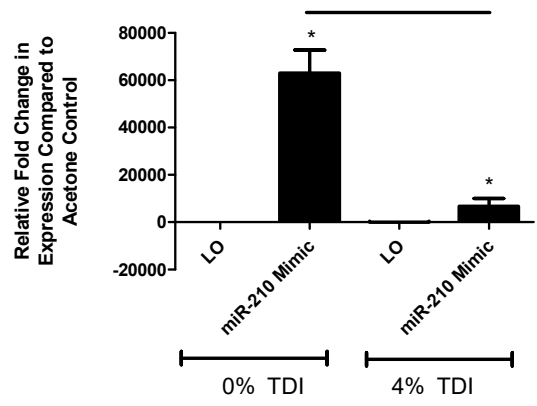

B

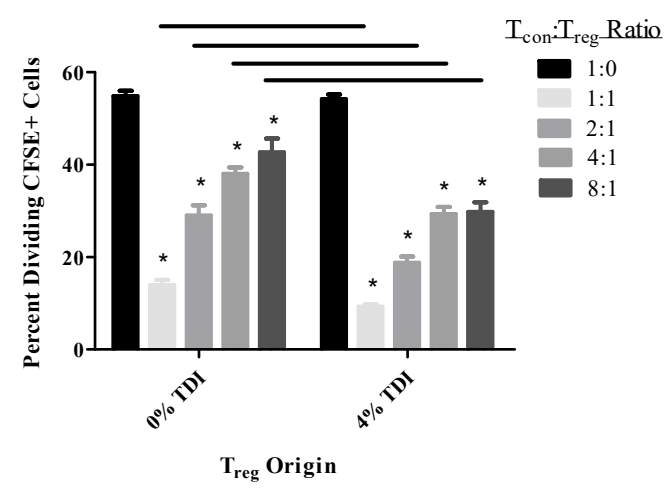

Figure 5. Increased $\mathrm{T}_{\text {reg }}$ suppression is associated with decreased miR-210 levels. A CFSE-based $\mathrm{T}_{\text {reg }}$ suppression assay was performed with $\mathrm{T}_{\text {regs }}$ from mice treated with acetone or TDI (seven days post exposure) and the addition of miR-210 mimic. RT-PCR analysis of intracellular miR-210 expression for acetone or TDI treated mice following addition of miR-210 mimic or Lipofectamine only (LO) control (A). Statistical significance is represented by horizontal lines comparing indicated groups and asterisks (compared to LO control) $(p<0.05)$. Functional capacity of $\mathrm{T}_{\text {regs }}$ based on percent dividing $\mathrm{CFSE}^{+}$naive conventional $\mathrm{T}$ cells $\left(\mathrm{T}_{\text {con }}\right)$ at indicated ratios following addition of miR-210 mimic (B). $p$ values are represented by ${ }^{*}(p<0.05$; comparison of each treatment group to 1:0 ratio from the same chemical treatment group) or horizontal bars (comparison of identical ratios between different mimic treatment groups). Bars represent mean relative fold change $( \pm \mathrm{SE})$ of three replicates per group.

\subsection{Further Investigation of miR-31 and -155 Suggest Additional Regulation of the TDI Sensitization} Response, Potentially Impacting miR-210 and $T_{\text {regs }}$

Evaluation of additional miRNAs was performed in an attempt to identify other potential factors that might influence miR-210 and $T_{\text {reg }}$ function. miR-31 and -155 were selected since they have 
been identified to significantly increase in dLN expression earlier in TDI sensitization compared to miRNA-210 (Figure 6A,B). Ex vivo target analysis was performed utilizing additional miRNA mimics including miR-31 and -155 in order to further pursue the potential regulation of the $\mathrm{T}_{\text {reg }}$ subset by these miRNAs in addition to miR-210. Significantly increased intracellular levels of miR-31 (Figure 6C) and miR-155 (Figure 6D) were confirmed $72 \mathrm{~h}$ following transfection and stimulation. Although not statistically significant, apparent decreases in foxp3 expression were observed following miR-31 (Figure 6E) and miR-155 (Figure 6F) mimic transfection. No changes in expression were observed for runx3, ctla4, or $c d 25$ following mimic addition (data not shown).

A

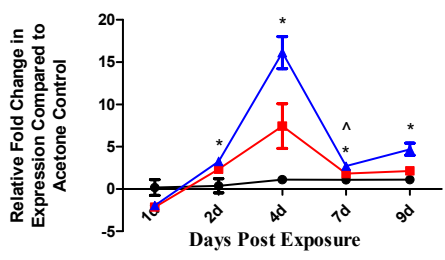

C

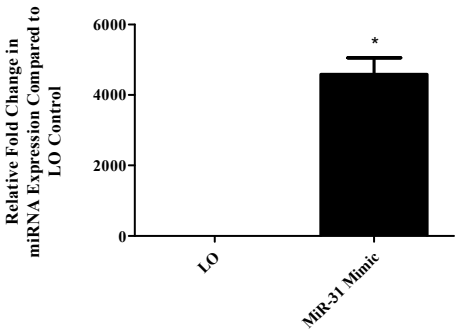

E

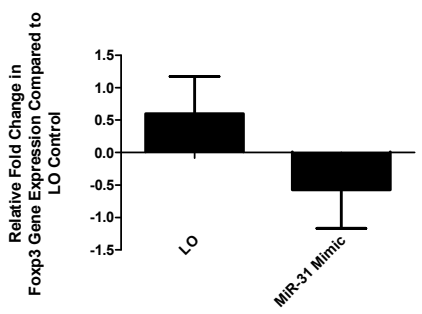

\section{B}

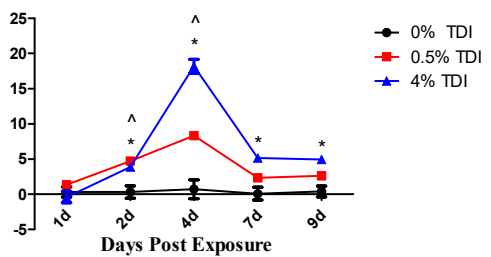

D

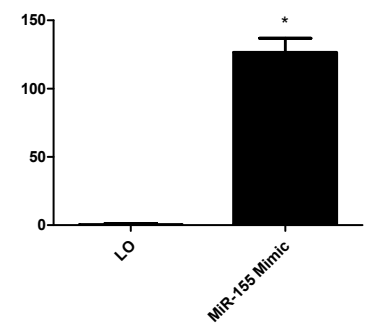

$\mathbf{F}$

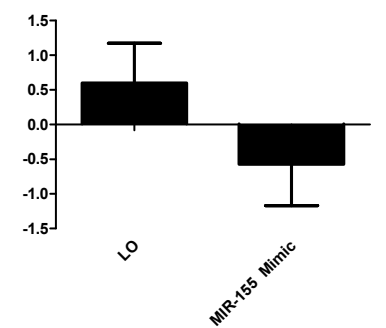

Figure 6. In vivo dLN miR-31 and -155 levels increase during TDI sensitization. Whole dLN miR-31 (A) and -155 (B) levels were quantified via RT-PCR at various time points post TDI sensitization. Statistical significance is represented by ${ }^{\wedge}\left(0.5 \%\right.$ TDI) and ${ }^{*}(4 \%$ TDI) compared to vehicle control $(p<0.05)$. Intracellular miR-31 (C), -155 (D) was quantified via RT-PCR in ex vivo stimulated samples (with miR-31 or - 155 mimic addition, respectively) after $72 \mathrm{~h}$. (D-F) foxp3 expression was investigated in cultures following miR-31 (D) and -155 (E) mimic treatment. Statistical significance is represented by * when compared to lipofectamine only (LO) control ( $p<0.05)$. ( $n=3-5 /$ group).

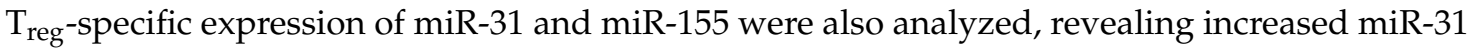
levels two and seven days post $0.5 \%$ TDI exposure (Figure 7A,B) and increased miR-155 levels seven days post $4 \%$ TDI exposure (Figure 7D). Since miR-31 was identified to increase in expression earlier than miR-210 in the $d L N$ and $T_{\text {regs }}$, miR-210 expression was evaluated in dLN cells treated with miR-31 and -155 mimics. However, no changes in expression were observed. Similarly, expression of miR-31 
and - 155 was analyzed in cells treated with miR-210 mimic but no significant changes in expression were observed (data not shown).

\section{Days}

A

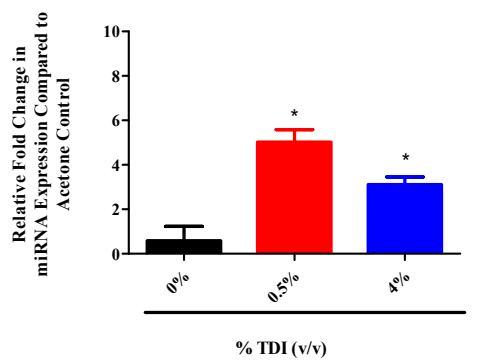

C

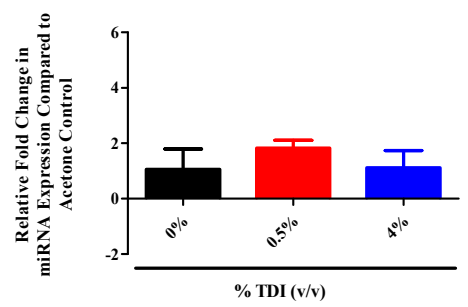

7 Days

B

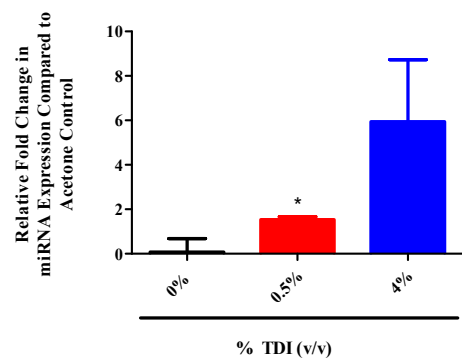

D

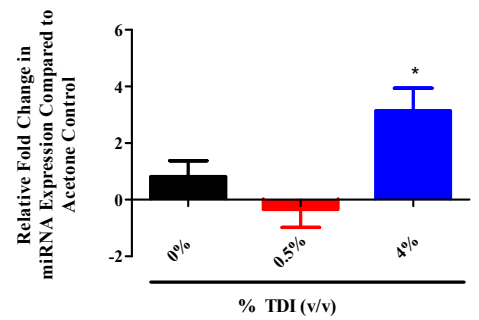

Figure 7. Mature miR-31 and -155 expression increases in $\mathrm{T}_{\text {regs }}$ during TDI sensitization. RT-PCR analysis of miR-31 (A,B) and -155 (C,D) expression in the dLN $\mathrm{T}_{\text {reg }}$ subset at two and seven days post TDI exposure. $\mathrm{T}_{\text {regs }}$ were isolated as $\mathrm{CD} 4{ }^{+} \mathrm{CD} 25^{+}$cells and cellular purity was assessed via flow cytometric staining for $\mathrm{CD}^{+} \mathrm{CD}^{+} \mathrm{Foxp}^{+}$events ( 2 days: $\% \mathrm{~T}_{\text {regs }}$ of all $\mathrm{CD}^{+}$events, mean, $n=4-5$ per group: Acetone: $83.8 \% \pm 1.6 \%, 0.5 \%$ TDI: $67.1 \% \pm 4.2 \%$, and $4 \%$ TDI: $72.3 \% \pm 1.9 \% ; 7$ days: $\%$ Tregs of all CD4 ${ }^{+}$events, Acetone: $91 \%, 0.5 \%$ TDI: $88.4 \%$, and $4 \%$ TDI: $86.7 \%$ ). Bars represent mean relative fold change ( \pm SE) of 4-5 mice per group. Statistical significance is represented by * $(p<0.05)$.

\section{Discussion}

The occupational use of sensitizing chemicals such as TDI remains a significant public health concern. There are no validated hazard identification strategies for respiratory sensitizers like TDI and the complete immunologic mechanisms of sensitization have not been elucidated for these agents, hindering development of appropriate preventative assays. This justifies research pertaining to the identification of novel cellular subsets and epigenetic regulatory mechanisms such as miRNAs that may be involved in the respiratory chemical sensitization process. Following the identification of several upregulated dLN miRNAs during TDI sensitization, these molecules were investigated, specifically in relation to $\mathrm{T}_{\text {reg }}$ development and functionality. To our knowledge, this is the first work that functionally investigates miRNAs in a model of TDI-induced chemical sensitization.

miRNAs are powerful regulatory molecules which have been implicated in a number of immunologic states and conditions, including allergic disease [24-26]. Specifically, miR-155 has demonstrated a critical role in the development of antibody responses and germinal center function [27], miR-326 has been shown to regulate Th17 differentiation, exhibiting critical involvement in multiple sclerosis pathogenesis [28], and in vivo miR-126 inhibition reduces a house dust mite-induced asthmatic phenotype, demonstrating the importance of this miRNA in the regulation of Th2 responses and allergic asthma [24]. Vennegaard et al. described upregulation of several miRNAs, including 
miR-21, in skin biopsies from patients with allergic responses to diphenylcyclopropenone and in a murine model of dinitrofluorobenzene (DNFB) allergic contact dermatitis [17]. Additionally, previous work from our groups identified upregulation of several miRNAs, including miR-31, -155, and -210, in a murine model of epicutaneous TDI sensitization [1]. These ubiquitous signaling molecules are well-established mediators of many of signaling pathways in a number of cell types; however, their role in chemical sensitization is not well understood. For the work described in this manuscript, miR-210 was selected for additional investigation since it has been predicted and demonstrated to

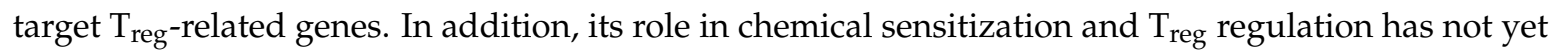
been described.

The expression of miR-210 was quantified in a variety of tissues and cellular subsets in a murine model of TDI sensitization. Consistent with previous findings [1], increased expression of miR-210 in the dLN was also demonstrated in the present study during TDI sensitization (Figure 1A). In addition, increased expression of miR-210 was also identified in $\mathrm{T}_{\text {regs }}$ during TDI sensitization (Figure 4A). Since miRNA can be transported to cells via mechanisms such as exosomal transport, experiments to determine if cells are actively producing miR-210 following TDI exposure were conducted. The expression of pri-miRNA indicates gene level expression, presumably within the cell type tested. Pri-miR-210 was detected in the dLN and CD4 ${ }^{+}$subsets four days post TDI exposure (Figure 1B), indicating that miR-210 is being expressed in this tissue by $\mathrm{CD}^{+} \mathrm{T}$ cells. Interestingly, although they were detectable, pri-miR-210 levels significantly decreased in CD4 ${ }^{+} \mathrm{T}$ cells four days post $4 \%$ TDI exposure compared to equivalent cells in acetone-exposed mice, potentially indicating that the majority of mature miR-210 in the $\mathrm{dLN}$ is being produced by another cell type, is being transported from another tissue, or is being transcriptionally downregulated at this point, the peak of mature miR-210 levels in the dLN. While pri-miR-210 levels in $\mathrm{T}_{\text {regs }}$ were not investigated in the current study, previous studies have demonstrated miR-210 expression following the polarization of naïve $\mathrm{T}$ cells into $\mathrm{T}_{\text {regs }}[29]$.

Since $\mathrm{T}_{\text {regs }}$ have been implicated as regulators of TDI sensitization [21] and miR-210 expression has been shown to increase in $\mathrm{T}_{\text {regs }}$ following TDI sensitization (Figure 4A), an ex vivo target analysis system was designed in order to directly examine the effects of miR-210 on $\mathrm{T}_{\text {reg-related genes. Selected }}$ genes identified as target of miR-210 included foxp3, the master transcription factor of the $\mathrm{T}_{\text {reg }}$ subset; and runx3, a transcription factor that signals upstream of foxp3 by binding to this gene's promoter [30]. Additionally, cd25 and ctla4 were investigated as important $\mathrm{T}_{\text {reg-related genes as they are involved }}$ in IL-2 signaling and proliferation along with direct suppressive functions, respectively. This setup

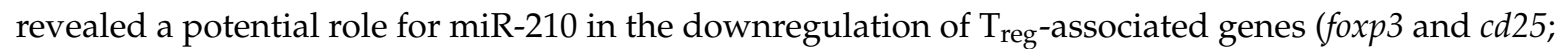
Figure 2B) following the addition of miR-210 mimic. In addition foxp3 and runx 3 dLN expression decreased in the dLN at various time points following TDI exposure (Figure 3A,B) which is consistent with our previously reported findings [21]. The earlier decrease in runx3 expression observed at four days post $4 \%$ TDI exposure may be reflective of the upstream signaling activity of this transcription factor in relation to foxp3 (Figure 3B). While the findings for the ex vivo assay did not reach statistical

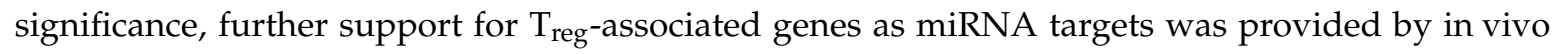
data. Interestingly, whole dLN expression of ctla4 and $c d 25$ increased at one, two and four days post 4\% TDI exposure (Figure 3C,D) which is likely a reflection of the activation of both $\mathrm{T}_{\text {regs }}$ and conventional $\mathrm{T}$ cells as elevated protein expression of these molecules is observed in $\mathrm{T}_{\text {regs }}$ at these time points [21] and would likely be increased in conventional $\mathrm{T}$ cells involved in TDI sensitization as well. In $\mathrm{T}_{\text {regs }}$, decreases in foxp3, cd25 and ctla4 were observed at two and seven days with runx3 only being decreased at the earlier time point post TDI exposure (Figure 4B). These early changes in $\mathrm{T}_{\text {reg }}$ factors provide further support that additional factors might be involved in $\mathrm{T}_{\text {reg }}$ regulation since peak increases in miR-210 occur later than two days; accordingly, miR-31 was shown be increased at this time point. In contrast to the transcript, the expression kinetics of Runx3 increased following TDI exposure (Figure 4D). This expression pattern was similar to other $\mathrm{T}_{\text {reg }}$ proteins such as CD25 and Foxp3 (which are represented by the general $\mathrm{T}_{\text {reg }}$ population) and $\mathrm{T}_{\text {reg-specific }}$ CTLA4 expression, 
which have previously been investigated during TDI sensitization [21]. The kinetics of $\mathrm{T}_{\text {regs }}$ bearing these molecules tended to peak at four days post TDI exposure with a relative decrease in both cellular frequency and number at seven days post TDI exposure [21]. In relation to miR-210 expression kinetics, this data may suggest that miR-210 has a regulatory role on the $T_{\text {reg }}$ subset, as its expression wanes in concert with the general $\mathrm{T}_{\text {reg }}$ population as well as CTLA4 ${ }^{+}$and Runx ${ }^{+} \mathrm{T}_{\text {regs. }}$. Additionally, miR-210 is a putative run $x 3$ target, suggesting a potential direct effect on this gene [1]. Collectively, this data is suggestive of $T_{\text {reg }}$ regulation with visible effects on the expression of proteins beginning at Day 7 post TDI exposure. miR-210 expression remains elevated in the dLN throughout nine days post $0.5 \%$ and $4 \%$ TDI exposure (Figure 1A) and in $\mathrm{T}_{\text {regs }}$ at seven days post $0.5 \%$ and $4 \%$ TDI exposure (Figure $4 \mathrm{~A}$ ).

Due to the potential link between miR-210 and $\mathrm{T}_{\text {reg-related gene expression, the functional }}$ capabilities of $\mathrm{T}_{\text {regs }}$ (acetone and TDI-derived) were examined in the presence and absence of miR-210 mimic. Interestingly, it appeared that miR-210 levels were lower in wells containing $\mathrm{T}_{\text {regs }}$ from TDI-treated mice and miR-210 mimic compared to wells with acetone-derived $T_{\text {regs }}$ and miR-210 mimic (Figure 5A). The increased suppressive capability of TDI $\mathrm{T}_{\text {regs }}$ with miR-210 mimic (Figure 5B) may be a reflection of reduced miR-210 levels, as we hypothesize that miR-210 is inhibiting $T_{\text {reg }}$ differentiation and/or function. This finding suggested that other regulatory factors including other miRNAs might be involved in the regulation of $T_{\text {reg }}$ function. Complex interactions and interplay have often been reported for other miRNAs [31], therefore this concept was evaluated in the current study. Typically, direct miRNA-miRNA interactions are mediated by reverse complementary binding, resulting in the formation of duplexes [31]. Additionally, indirect miRNA-miRNA interaction may occur via target gene interaction; e.g., if a miRNA targets a gene that induces a different miRNA, this miRNA is being regulated by its own species.

miRNA-31 and-155 were further investigated for the potential to regulate the expression of miR-210 as they were identified to increase at early time points in TDI sensitization in the dLN (Figure 6A (miR-31) and B (miR-155)) and $\mathrm{T}_{\text {regs }}$ (Figure 7A (miR-31)). Similarly to miR-210, miR-31 and -155 were shown to potentially downregulate foxp3 expression in this assay (Figure 6E,F). Although limitations in the assay sensitivities did not reflect significant changes, this may be reflective of a direct effect on foxp3 or an indirect effect on this gene via other signaling pathways such as miR-210. These alterations are in accordance with recent findings pertaining to miRNA-mRNA interactions. miR-31 may indirectly target foxp3, leading to suppressed $\mathrm{iT}_{\text {reg }}$ development [19], accounting for the potential decreases in this gene evidenced following miR-31 mimic transfection. In addition, miR-31 increases earlier when more persistent decreases in foxp 3 were observed. Additionally, miR-155 expression appears to be controlled by foxp 3 in $\mathrm{T}_{\text {regs }}$ via binding to the intron within the DNA sequence encoding Bic, the precursor transcript of miR-155; accordingly, $\mathrm{T}_{\text {reg }} \mathrm{miR}-155$ levels have been shown to be highly responsive to foxp3 levels [32]. This regulation may be interrupted by abnormally high levels of miR-155 in the mimic transfection system, resulting in decreased foxp 3 expression in these conditions via signaling feedback. This data suggests that miR-31 and -155 may be influencing the expression of miR-210 and/or $T_{\text {regs, }}$ possibly acting as early signaling mediators in the TDI sensitization response.

The lack of significance associated with the ex vivo experiments conducted in this work could be a reflection of experimental variability associated with similar assays and temporal discrepancies associated with signaling events. The ex vivo system displays several limitations, explaining the utilization of the in vivo TDI sensitization model in the target investigation as well. The $\mathrm{T}_{\text {reg-related }}$ gene alterations that were observed as a consequence of miRNA mimic transfections in this system may indicate direct and/or indirect targeting by the miRNA. We propose that for the majority of miRNA-mRNA interactions investigated in our model, regulation is indirect, as few, if any, putative binding sites were identified for many of the potential targets and the corresponding miRNA. For example, miR-210 is predicted to target the $3^{\prime}$ UTR of runx3 [1] and although we did not observe significant alterations in runx3 expression following miR-210 mimic transfection in our ex vivo system, the in vivo expression kinetics of runx 3 suggest potential regulation. The ubiquitous nature of miRNAs 
and their involvement in various signaling processes accounts for their functional significance but can also cloud investigations into their mechanistic functions.

It is important to note that the increases in miRNA expression were not dependent on the irritant response, as dLN miR-210 levels significantly increased (Figure 4A) following the non-irritating [21] $0.5 \%$ TDI exposure. As 4\% TDI exposure causes significant dermal irritation [21], ear miR-210 expression was analyzed at both non-irritant $(0.5 \%)$ and irritant $(1 \%, 2 \%$, and $4 \%)$ TDI concentrations, revealing significant increases in dLN at both non-irritant and irritant doses (Figure 1A). In addition, other miRNAs including miR-22, -31, and -301a were also shown to increase significantly in expression regardless of the irritant status of the TDI dose (data not shown). This data prompts insight into the concept of the "two-signal" sensitization hypothesis which states that antigen delivery alone is insufficient for effective immunological priming but rather a second, innate signal is necessary to ensure the development of sensitization [33,34]. As noted in previous studies, the irritant response appears to be a prerequisite for strong sensitization responses in the case of dermal TDI sensitization [21]. Regardless, the expression of multiple miRNAs in the dLN appears to be due to the sensitization response alone and not significantly influenced by the irritant component of this response, which may be revealing as to their supposed functional roles in the sensitization response and may suggest potential utility as biomarkers of sensitization.

These studies reveal a potential role for miR-210 in a murine model of dermal TDI sensitization (Figure 8). Additionally, miR-31 and miR-155 were investigated for their regulatory potential in this response. The investigation of novel mediators of chemical-induced allergic disease is important for the overall understanding of the mechanisms involved in these responses. Therefore, this data may result in enhanced understanding of the mechanisms involved in chemical sensitization and could potentially aid in the development of hazard identification strategies for respiratory chemical sensitizers. In conclusion, we have demonstrated that miR-210 may negatively influence the differentiation and/or function of $\mathrm{T}_{\text {regs }}$ via direct targeting of run $x 3$ and/or indirect actions on other

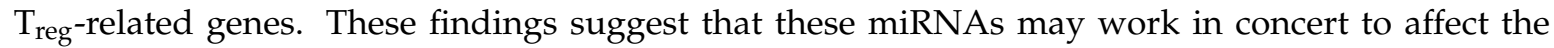
differentiation and function of $\mathrm{T}_{\text {regs }}$ as well as the expression and function of miR-210.

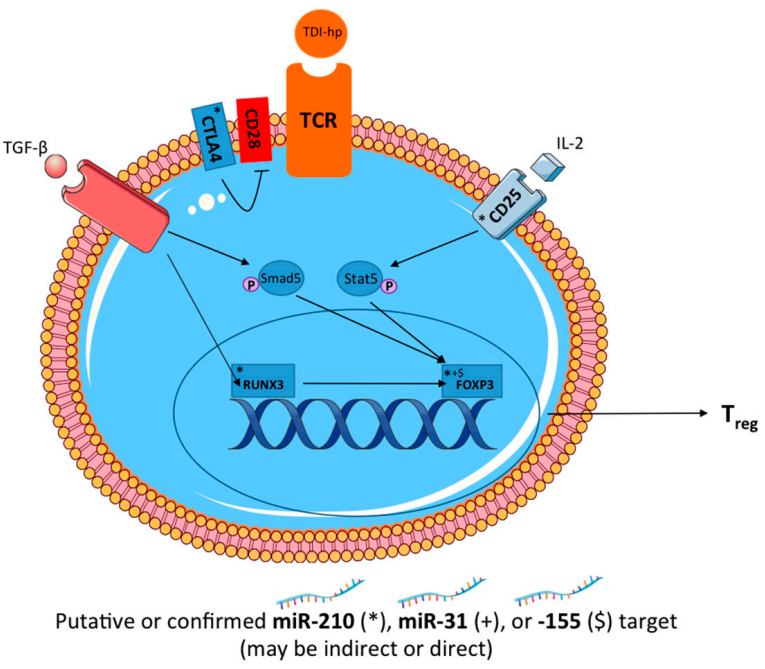

Figure 8. Proposed model of selected miRNA action on the regulatory $\mathrm{T}$ cell pathway. Integral components of the $\mathrm{T}_{\text {reg }}$ activation pathway are highlighted alongside putative direct targets or key players indirectly impacted by miRNA-210 (indicated by *), -31 (indicated by + ), and -155 (indicated by \$). Legend: CD28, Cluster of differentiation 28; CD25, IL-2 receptor alpha (in complex with IL-2R $\beta$ and

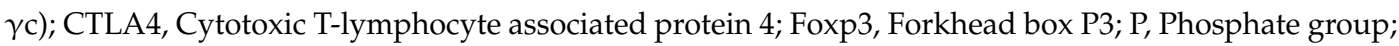
Runx3, Runt related transcription factor 3; Smad5, Mothers against decapentaplegic homolog 5; Stat5, Signal transducer and activator of transcription 5, TCR, T cell receptor; TDI-hp, Toluene diisocyanate haptenated complex; TGF- $\beta 1$, Transforming growth factor beta 1 . 
Acknowledgments: This work was supported by National Institute for Occupational Safety and Health (NIOSH) intramural funds. The findings and conclusions of this article do not necessarily represent the views of the National Institute of Occupational Safety and Health.

Author Contributions: C.M.L., N.B.M., and S.E.A. conceived and designed the experiments; C.M.L., E.L., N.B.M., and S.E.A. performed the experiments; C.M.L. and S.E.A. analyzed the data; A.N. contributed reagents and analysis; and C.M.L. wrote the paper.

Conflicts of Interest: The authors declare no conflict of interest.

\section{References}

1. Anderson, S.E.; Beezhold, K.; Lukomska, E.; Richardson, J.; Long, C.; Anderson, K.; Franko, J.; Meade, B.J.; Beezhold, D.H. Expression kinetics of miRNA involved in dermal toluene 2,4-diisocyanate sensitization. J. Immunotoxicol. 2013, 11, 250-259. [CrossRef] [PubMed]

2. Johnson, V.J.; Yucesoy, B.; Reynolds, J.S.; Fluharty, K.; Wang, W.; Richardson, D.; Luster, M.I. Inhalation of toluene diisocyanate vapor induces allergic rhinitis in mice. J. Immunol. 2007, 179, 1864-1871. [CrossRef] [PubMed]

3. U.S. Environmental Protection Agency. Toluene Diisocyanate (TDI) and Related Compounds Action Plan; RIN 2070-za14; U.S. Environmental Protection Agency: Washington, DC, USA, 2011.

4. Mapp, C.E. Agents, old and new, causing occupational asthma. Occup. Environ. Med. 2001, 58, 354. [CrossRef] [PubMed]

5. Kim, S.H.; Choi, G.S.; Ye, Y.M.; Jou, I.; Park, H.S.; Park, S.M. Toluene diisocyanate (TDI) regulates haem oxygenase-1/ferritin expression: Implications for toluene diisocyanate-induced asthma. Clin. Exp. Immunol. 2010, 160, 489-497. [CrossRef] [PubMed]

6. Network Time Protocol (NTP). Report on Carcinogens, 12th ed.; National Toxicology Program; U.S. Department of Health and Human Services: Research Triangle Park, NC, USA, 2011; p. 499.

7. Bello, D.; Herrick, C.A.; Smith, T.J.; Woskie, S.R.; Streicher, R.P.; Cullen, M.R.; Liu, Y.; Redlich, C.A. Skin exposure to isocyanates: Reasons for concern. Environ. Health Perspect. 2007, 115, 328-335. [CrossRef] [PubMed]

8. Anderson, S.E.; Meade, B.J. Potential health effects associated with dermal exposure to occupational chemicals. Environ. Health Insights 2014, 8, 51-62. [CrossRef] [PubMed]

9. Vandebriel, R.J.; De Jong, W.H.; Spiekstra, S.W.; Van Dijk, M.; Fluitman, A.; Garssen, J.; Van Loveren, H. Assessment of preferential T-helper 1 or T-helper 2 induction by low molecular weight compounds using the local lymph node assay in conjunction with RT-PCR and ELISA for interferon- $\gamma$ and interleukin-4. Toxicol. Appl. Pharmacol. 2000, 162, 77-85. [CrossRef] [PubMed]

10. Karol, M.H.; Hauth, B.A.; Riley, E.J.; Magreni, C.M. Dermal contact with toluene diisocyanate (TDI) produces respiratory tract hypersensitivity in guinea pigs. Toxicol. Appl. Pharmacol. 1981, 58, 221-230. [CrossRef]

11. Anderson, S.E.; Siegel, P.D.; Meade, B.J. The LLNA: A brief review of recent advances and limitations. J. Allergy 2011, 2011, 424203. [CrossRef] [PubMed]

12. Kopriva, S.E.; Chiasson, V.L.; Mitchell, B.M.; Chatterjee, P. TLR3-induced placental miR-210 down-regulates the STAT6/interleukin-4 pathway. PLoS ONE 2013, 8, e67760. [CrossRef] [PubMed]

13. Qi, J.; Qiao, Y.; Wang, P.; Li, S.; Zhao, W.; Gao, C. MicroRNA-210 negatively regulates LPS-induced production of proinflammatory cytokines by targeting NF-kB1 in murine macrophages. FEBS Lett. 2012, 586, 1201-1207. [CrossRef] [PubMed]

14. Taganov, K.D.; Boldin, M.P.; Baltimore, D. MicroRNAs and immunity: Tiny players in a big field. Immunity 2007, 26, 133-137. [CrossRef] [PubMed]

15. Baltimore, D.; Boldin, M.P.; O'Connell, R.M.; Rao, D.S.; Taganov, K.D. MicroRNAs: New regulators of immune cell development and function. Nat. Immunol. 2008, 9, 839-845. [CrossRef] [PubMed]

16. Xiao, C.; Rajewsky, K. MicroRNA control in the immune system: Basic principles. Cell 2009, 136, 26-36. [CrossRef] [PubMed]

17. Vennegaard, M.T.; Bonefeld, C.M.; Hagedorn, P.H.; Bangsgaard, N.; Lovendorf, M.B.; Odum, N.; Woetmann, A.; Geisler, C.; Skov, L. Allergic contact dermatitis induces upregulation of identical microRNAs in humans and mice. Contact Dermat. 2012, 67, 298-305. [CrossRef] [PubMed] 
18. Lodish, H.F.; Zhou, B.; Liu, G.; Chen, C.Z. Micromanagement of the immune system by microRNAs. Nat. Rev. Immunol. 2008, 8, 120-130. [CrossRef] [PubMed]

19. Zhang, L.; Ke, F.; Liu, Z.; Bai, J.; Liu, J.; Yan, S.; Xu, Z.; Lou, F.; Wang, H.; Zhu, H.; et al. MicroRNA-31 negatively regulates peripherally derived regulatory $\mathrm{T}$-cell generation by repressing retinoic acid-inducible protein 3. Nat. Commun. 2015, 6, 7639. [CrossRef] [PubMed]

20. Christensen, A.D.; Skov, S.; Kvist, P.H.; Haase, C. Depletion of regulatory T cells in a hapten-induced inflammation model results in prolonged and increased inflammation driven by T cells. Clin. Exp. Immunol. 2015, 179, 485-499. [CrossRef] [PubMed]

21. Long, C.M.; Marshall, N.B.; Lukomska, E.; Kashon, M.L.; Meade, B.J.; Shane, H.; Anderson, S.E. A role for regulatory $\mathrm{T}$ cells in a murine model of epicutaneous toluene diisocyanate sensitization. Toxicol. Sci. Off. J. Soc. Toxicol. 2016, 152, 85-98. [CrossRef] [PubMed]

22. Anderson, S.E.; Umbright, C.; Sellamuthu, R.; Fluharty, K.; Kashon, M.; Franko, J.; Jackson, L.G.; Johnson, V.J.; Joseph, P. Irritancy and allergic responses induced by topical application of ortho-phthalaldehyde. Toxicol. Sci. Off. J. Soc. Toxicol. 2010, 115, 435-443. [CrossRef] [PubMed]

23. Franko, J.; Jackson, L.G.; Hubbs, A.; Kashon, M.; Meade, B.J.; Anderson, S.E. Evaluation of furfuryl alcohol sensitization potential following dermal and pulmonary exposure: Enhancement of airway responsiveness. Toxicol. Sci. Off. J. Soc. Toxicol. 2012, 125, 105-115. [CrossRef] [PubMed]

24. Mattes, J.; Collison, A.; Plank, M.; Phipps, S.; Foster, P.S. Antagonism of microRNA-126 suppresses the effector function of Th2 cells and the development of allergic airways disease. Proc. Natl. Acad. Sci. USA 2009, 106, 18704-18709. [CrossRef] [PubMed]

25. Lu, T.X.; Rothenberg, M.E. Diagnostic, functional, and therapeutic roles of microRNA in allergic diseases. J. Allergy Clin. Immunol. 2013, 132, 3-13. [CrossRef] [PubMed]

26. Zech, A.; Ayata, C.K.; Pankratz, F.; Meyer, A.; Baudiss, K.; Cicko, S.; Yegutkin, G.G.; Grundmann, S.; Idzko, M. MicroRNA-155 modulates P2R signaling and Th2 priming of dendritic cells during allergic airway inflammation in mice. Allergy 2015, 70, 1121-1129. [CrossRef] [PubMed]

27. Thai, T.H. Regulation of the germinal center response by microRNA-155. Science 2007, 316, 604-608. [CrossRef] [PubMed]

28. Du, C.; Liu, C.; Kang, J.; Zhao, G.; Ye, Z.; Huang, S.; Li, Z.; Wu, Z.; Pei, G. MicroRNA miR-326 regulates Th-17 differentiation and is associated with the pathogenesis of multiple sclerosis. Nat. Immunol. 2009, 10, 1252-1259. [CrossRef] [PubMed]

29. Wang, H.; Flach, H.; Onizawa, M.; Wei, L.; McManus, M.T.; Weiss, A. Negative regulation of HIF1A expression and Th17 differentiation by the hypoxia-regulated microRNA miR-210. Nat. Immunol. 2014, 15, 393-401. [CrossRef] [PubMed]

30. Bruno, L.; Mazzarella, L.; Hoogenkamp, M.; Hertweck, A.; Cobb, B.S.; Sauer, S.; Hadjur, S.; Leleu, M.; Naoe, Y.; Telfer, J.C.; et al. Runx proteins regulate Foxp3 expression. J. Exp. Med. 2009, 206, 2329-2337. [CrossRef] [PubMed]

31. Guo, L.; Zhao, Y.; Yang, S.; Zhang, H.; Chen, F. Integrative analysis of miRNA-mRNA and miRNA-miRNA interactions. BioMed Res. Int. 2014, 2014, 907420. [CrossRef] [PubMed]

32. Lu, L.-F.; Thai, T.-H.; Calado, D.P.; Chaudhry, A.; Kubo, M.; Tanaka, K.; Loeb, G.B.; Lee, H.; Yoshimura, A.; Rajewsky, K.; et al. Foxp3-dependent microRNA155 confers competitive fitness to regulatory $\mathrm{T}$ cells by targeting SOCS1 protein. Immunity 2009, 30, 80-91. [CrossRef] [PubMed]

33. Kimber, I.; Basketter, D.A.; McFadden, J.P.; Dearman, R.J. Characterization of skin sensitizing chemicals: A lesson learnt from nickel allergy. J. Immunotoxicol. 2011, 8, 1-2. [CrossRef] [PubMed]

34. McFadden, J.P.; Basketter, D.A. Contact allergy, irritancy and 'danger'. Contact Dermat. 2000, 42, $123-127$. [CrossRef]

(C) 2016 by the authors; licensee MDPI, Basel, Switzerland. This article is an open access article distributed under the terms and conditions of the Creative Commons Attribution (CC-BY) license (http://creativecommons.org/licenses/by/4.0/). 